University of Nebraska - Lincoln

DigitalCommons@University of Nebraska - Lincoln

Faculty Papers and Publications in Animal

Science

Animal Science Department

May 1992

\title{
Differences in Heritability Estimates from Multiple-Trait and Repeated-Records Models
}

\author{
L. Dale Van Vleck \\ University of Nebraska-Lincoln, dvan-vleck1@unl.edu \\ K. E. Gregory \\ Roman L. Hruska U.S. Meat Animal Research Center, USDA-ARS
}

Follow this and additional works at: https://digitalcommons.unl.edu/animalscifacpub

Part of the Animal Sciences Commons

Van Vleck, L. Dale and Gregory, K. E., "Differences in Heritability Estimates from Multiple-Trait and Repeated-Records Models" (1992). Faculty Papers and Publications in Animal Science. 245.

https://digitalcommons.unl.edu/animalscifacpub/245

This Article is brought to you for free and open access by the Animal Science Department at DigitalCommons@University of Nebraska - Lincoln. It has been accepted for inclusion in Faculty Papers and Publications in Animal Science by an authorized administrator of DigitalCommons@University of Nebraska - Lincoln. 


\title{
Differences in Heritability Estimates from Multiple-Trait and Repeated-Records Models ${ }^{1}$
}

\author{
L. D. Van Vleck* and K. E. Gregory ${ }^{\dagger}$ \\ Roman L. Hruska U.S. Meat Animal Research Center, ARS, USDA, \\ *Lincoln, NE 68583-0908 and tClay Center, NE 68933-0166
}

\begin{abstract}
Analyses of ovulation rates in consecutive estrous cycles with multiple-trait and repeated-records animal models resulted in different estimates of heritability. The estimate from the repeated-records model was seen to be approximately the product of the average genetic correlation and the average heritability from the multipletrait procedure. A simple model is used to show
\end{abstract}

algebraically that such a result is expected, particularly if the environmental correlations are small among records of the same animal. Comparison of results of the two types of analyses of 10 replications of 10 combinations of underlying heritabilities and genetic correlations confirms this explanation.

\section{Key Words: Variance Components, Estimation, Animal Models, Genetic Correlation, Repeatability}

J. Anim. Sci. 1992. 70:2994-2998

\section{Introduction}

Analyses of measures of ovulation rate in consecutive estrous cycles of heifers in the twinning project at the U.S. Meat Animal Research Center (Van Vleck et al., 1991) with two different models produced different estimates of heritability. Analysis with a multivariate animal model with ovulation rate at each of eight consecutive estrous cycles considered as different traits resulted in an average heritability estimate of .16 for the eight cycles. The average of the 28 phenotypic and genetic correlations among the eight cycles were .12 and .66. Analysis with a repeated-records animal model, conversely, resulted in an estimate of heritability of .10 and repeatability of .12 . The multiple-trait analysis included eight measures on 610 heifers and the repeated-records analysis included 840 heifers with an average of 8.23 records so that some had fewer and others more than eight records. Despite the relatively small sample sizes and the difference in data, a reason for the difference in estimates of heritability was wanted. What was

\footnotetext{
${ }^{1}$ Published as Paper No. 9537, Journal Ser., Nebraska Agric. Res. Div., Univ. of Nebraska, Lincoln 68583-0908.

Received January 28, 1892.

Accepted May 26, 1982.
}

first noticed was that among the eight measures there were no obvious patterns in the genetic and environmental correlations. Intuitively, heritability would be expected to be the same for each cycle and the genetic correlations between pairs of cycles over a time period of only $24 \mathrm{wk}$ would be expected to be nearly unity. The observations, however, were either 1 or 2 and were not continuous. The average estimate of genetic correlation multiplied by the average estimate of heritability was similar to the estimate of heritability from the repeated records model: $(.66)(.16)=.1056$. Also, the average phenotypic correlation of .12 from the multitrait model was the same as repeatability from the repeated-records model, as would be expected. The purpose of this paper is to provide an approximate statistical explanation for such a result. That explanation was then tested by comparing estimates from the multiple-trait analysis with estimates from the repeated-records model for 100 sets of records simulated with the design based on actual measures of ovulation rate on 610 heifers.

\section{Materials and Methods}

Statistical Explanation. The following model and development are simpler than the actual models used but should be sufficient to show why the 
Table 1. Expectations of quadratics and estimates of variance components for a one-way (animal) classification model when covariances

between records on the same animal are $\sigma_{\mathrm{gg}}+\sigma_{\mathrm{ee}}$

\begin{tabular}{lccccc}
\hline \hline & \multicolumn{5}{c}{ Coefficients of } \\
\cline { 2 - 6 } Quadratic $^{\mathbf{a}}$ & $\mu^{2}$ & $\sigma_{\mathrm{g}}^{2}$ & $\sigma_{\mathrm{gg}}$ & $\sigma_{\mathrm{\theta}}^{2}$ & $\sigma_{\mathrm{ee^{ \prime }}}$ \\
\hline (1) $\sum_{1} \sum_{1} \mathrm{y}_{\mathrm{ij}}^{2}$ & $\mathrm{bn}$ & $\mathrm{bn}$ & 0 & $\mathrm{bn}$ & 0 \\
(2) $\sum_{1}\left(\mathrm{y}_{\mathrm{i}}^{2} / \mathrm{n}\right)$ & $\mathrm{bn}$ & $\mathrm{b}$ & $\mathrm{b}(\mathrm{n}-1)$ & $\mathrm{b}$ & $\mathrm{b}(\mathrm{n}-1)$ \\
(3) $\mathrm{y}^{2} . / \mathrm{bn}$ & $\mathrm{bn}$ & 1 & $\mathrm{n}-1$ & 1 & $\mathrm{n}-1$ \\
$(4)=[(1)-(2)] /[\mathrm{b}(\mathrm{n}-1)]$ & 0 & 1 & -1 & 1 & -1 \\
$(5)=[(2)-(3)-(\mathrm{b}-1)(4)] / \ln (\mathrm{b}-1)]$ & 0 & 0 & 1 & 0 & 1 \\
$(6)=(4)+(5)$ & 0 & 1 & 0 & 1 & 0 \\
\hline
\end{tabular}

$a_{44)}$ is usual predictor of within class variance, (5) is usual predictor of among class variance, and $(6)$ is predictor of total or phenotypic variance.

$b_{b}$ is the number of classes; $n$ is the number per class.

average genetic correlation multiplied by the average heritability from a multiple-trait model may be a good prediction of heritability from a repeated-records model. Let a simple one-way classification model be:

$y_{i j}=\mu+g_{i j}+e_{i j}$ with $i=1, \ldots, b$ and $j=1, \ldots, n$

with $\mathrm{y}_{\mathrm{ij}}$ the $\mathrm{j}^{\text {th }}$ record on animal $\mathrm{i}, \mathrm{g}_{\mathrm{ij}}$ the genetic value for the $j^{\text {th }}$ record on animal $i$, and $e_{i j}$ the environmental effect on the $j^{\text {th }}$ record on animal $i$.

Further assume equal heritability for each record and equal environmental and genetic covariances between all possible pairs of records on the same animal:

$$
\begin{aligned}
V\left(e_{i j}\right)= & \sigma_{e}^{2} \text { and } V\left(g_{i j}\right)=\sigma_{g}^{2} \\
\operatorname{CoV}\left(e_{i j}, e_{i j}\right)= & \sigma_{e e^{\prime}} \text { and } \operatorname{COV}\left(g_{i j}, g_{i j^{\prime}}\right)=\sigma_{g g^{\prime}} \\
& \text { for } j \neq j^{\prime}
\end{aligned}
$$

$\operatorname{Cov}\left(e_{i k}, e_{i^{\prime}}\right)=0, \operatorname{COV}\left(g_{i k}, g_{i^{\prime}}\right)=0$ for $i \neq i^{\prime}$ (this assumes animals are unrelated, which will not be true for all animals in the animal model ana. lyses).

This model is equivalent to the usual repeatedrecords model when $\sigma_{g g^{\prime}}=\sigma_{g}^{2}$ (i.e., a genetic correlation of unity between records).

The three quadratics used for a between- and within-animal model using Henderson's Method 1 (Henderson, 1953) are shown in Table 1 with their expectations under the correct model.

Table 1 shows that the expectations of the estimators are as follows:

$$
\begin{aligned}
& \text { [4]: } \mathrm{E}\left[\sigma_{\mathrm{w}}^{2}\right]=\left(1-\mathrm{r}_{\mathrm{g}}\right) \sigma_{\mathrm{g}}^{2}+\left(1-\mathrm{r}_{\mathrm{e}}\right) \sigma_{\mathrm{e}}^{2} \text { and } \\
& \text { [5]: } \mathrm{E}\left[\tilde{\sigma}_{\mathrm{a}}^{2}\right]=\mathrm{r}_{\mathrm{g}} \sigma_{\mathrm{g}}^{2}+\mathrm{r}_{\mathrm{e}} \sigma_{\mathrm{e}}^{2}
\end{aligned}
$$

where $r_{g}=\sigma_{g g^{\prime}} / \sigma_{g}^{2}$ and $r_{\theta}=\sigma_{e e^{\prime}} / \sigma_{e}^{2}$. If the genetic and environmental covariances among the traits are not equal for all pairs of traits, the expectations depend on the covariance patterns. Repeatability estimated from this model would be $\sigma_{a}^{2} /\left(\hat{\sigma}_{a}^{2}+\right.$ $\hat{\sigma}_{w}^{2}$ ) with expectations (taken separately for the numerator and denominator): $\left(r_{g} \sigma_{g}^{2}+r_{e} \sigma_{e}^{2}\right) /\left(\sigma_{g}^{2}+\sigma_{e}^{2}\right)$. The usual repeated records model assumes $r_{\mathrm{g}}=1$ and a common environmental covariance among pairs of measures. If $r_{e}$ is nearly zero, then what was observed in the analyses of actual data would correspond to the estimate of heritability (i.e., $h_{R}^{2} \simeq$ $\left(r_{g} h^{2}\right)_{M}$ with $h_{R}^{2}$, the heritability for the repeated measures model, and $\left(r_{g} h^{2}\right)_{M}$, the product of the average genetic correlation and average heritability for the multiple-trait model).

With this model, the phenotypic correlations between pairs of measures are $\left(r_{g} \sigma_{g}^{2}+r_{\theta} \sigma_{\theta}^{2}\right) /\left(\sigma_{g}^{2}+\right.$ $\sigma_{\mathrm{e}}^{2}$ ) for both the repeated-measures and multipletrait models. Thus, if $\left(r_{g} h^{2}\right)_{M}$ is used to predict $h_{R}^{2}$, then $\left(r_{p}\right)_{M}-\left(r_{g} h^{2}\right)_{M}$ could be used to predict $c_{R}^{2}$, the fraction of variance due to permanent environmental effects in the repeated-records model. These predictors from the multiple-trait model assuming equal heritabilities and genetic and phenotypic correlations were then compared with those obtained from a repeated-records animal model for 100 sets of simulated data (10 combinations of underlying parameters with 10 replicates).

Simulated Data. Simulated data sets from a previous study of the effect of transforming multivariate, normal variables to multivariate, binomially distributed variables on estimates of heritability and genetic and phenotypic correlations were available. The simulation procedure was described 
Table 2. Mean estimates for a repeated-records animal model of heritability $\left(\mathrm{h}^{2}\right)_{R}$, relative permanent environmental variance $\left\langle\left. c^{2}\right|_{R}\right.$, and repeatability $\left(\left.\mathbf{r}\right|_{R}\right.$ from 10 replications of data sets simulated with 10 combinations of parameters for underlying multivariate normal distribution $(\mathrm{N})$ truncated to eight binomial records on each animal: predictions of estimates for the repeated records model from estimates from multivariate analyses $(M)$ are in the middle three columns

\begin{tabular}{|c|c|c|c|c|c|c|c|c|}
\hline \multicolumn{3}{|c|}{$\begin{array}{l}\text { Parameters on underlying } \\
\text { multivariate normal scale }\end{array}$} & \multicolumn{3}{|c|}{$\begin{array}{l}\text { Average predictions from } \\
\text { estimates for multivariate } \\
\text { model on binomial scale } \\
\end{array}$} & \multicolumn{3}{|c|}{$\begin{array}{l}\text { Average estimates from } \\
\text { repeated records model } \\
\text { on binomial scale }\end{array}$} \\
\hline$\left(\mathrm{h}^{2}\right)_{\mathrm{N}}$ & $\left.{ }^{\prime}{ }_{g}\right)_{N}$ & $\left(r_{p}\right)_{N}$ & $\left(\mathrm{~h}^{2} \mathbf{r}_{g_{M}{ }_{M}}\right.$ & $\left(r_{p}-h^{2} r_{g}\right)_{M}$ & $\left(r_{p}\right)_{M}$ & $\left(h^{2}\right)_{R}$ & $\left(c^{2}\right)_{R}$ & $(\mathbf{r})_{R}$ \\
\hline .15 & .50 & .20 & .030 & .084 & .095 & .034 & .060 & .084 \\
\hline .15 & $.6 \overline{6}$ & .20 & .045 & .054 & .098 & .050 & .048 & .088 \\
\hline .15 & .80 & .20 & .047 & .043 & .090 & .050 & .040 & .080 \\
\hline .25 & .50 & .20 & .057 & .044 & .101 & .065 & .038 & .101 \\
\hline .25 & $.6 \overline{8}$ & .20 & .064 & .027 & .081 & .064 & .025 & $.08 \theta$ \\
\hline .25 & .80 & .20 & .080 & .013 & .093 & .082 & .011 & .083 \\
\hline .35 & .50 & .25 & .085 & .047 & .112 & .075 & .038 & .111 \\
\hline .35 & $.6 \overline{6}$ & .25 & .104 & .020 & .123 & .105 & .017 & .123 \\
\hline .35 & .80 & .25 & .138 & -.017 & .122 & .117 & .002 & .118 \\
\hline .25 & 1.00 & .25 & .117 & .005 & .122 & .112 & .009 & .121 \\
\hline
\end{tabular}

${ }^{\mathbf{a}}$ Average for 10 replicates.

more fully by Van Vleck and Gregory (1982). In summary, eight records per animal were simulated for a multivariate, normal distribution with parameters shown on the left three columns of Table 2. The normal variables then were assigned by truncation to a binomial scale so that approximately $85 \%$ were $1 \mathrm{~s}$ and $15 \%$ were $2 \mathrm{~s}$. The design matrices and numerator relationship matrix corresponded to the multivariate analysis of numbers of ovulations ( 1 or 2) measured in eight consecu. tive estrous cycles reported by Van Vleck et al. (1991). Three fixed factors with a total of 16 levels were included in the model. Of the 1,071 animals included in the numerator relationship matrix, 610 had records. Estimates of heritability and genetic and phenotypic correlations were obtained with multiple-trait REML (K. Meyer, personal communication, 1985, 1986) for 10 replicates of each combination of underlying heritability $(.15, .25, .35)$ and genetic correlation $(.50, .6 \overline{6}$, and .90$)$ among pairs of records. The phenotypic correlation was set to .20 for all analyses, except that for the last four combinations .25 was used to keep the covariance matrices positive definite. For the analyses reported here, a repeated-records animal model fixed effects plus additive genetic value plus permanent environmental effect plus random environmental effect) was used to estimate genetic $\left(\mathrm{h}^{2} \sigma^{2}\right)$ and permanent environmental $\left(\mathrm{c}^{2} \sigma^{2}\right)$ variances, which added together estimate the covariance between phenotypic records on the same animal. The DFREML programs of K. Meyer (1988, 1989 , personal communication), derived from the method described by Smith and Graser (1986) and Graser et al. (1887), were used. After some experience, to reduce the number of rounds to obtain convergence, starting values of $\left(r_{g} h^{2}\right)_{M}$ and $\left(r_{p}-\right.$ $\left.\mathrm{r}_{\mathrm{g}} \mathrm{h}^{2}\right)_{\mathrm{M}}$ obtained by multiple-trait REML with the same data set were used for $\left(h^{2}\right)_{R}$ and $\left(c^{2}\right)_{R}$. The average starting values and $\left(r_{p}\right)_{M}$ for each combination of parameters are shown in the middle three columns of Table 2. The same solutions should be obtained with any other positive starting values.

\section{Results and Discussion}

Simulation results are summarized in the last three columns of Table 2 (average of $h^{2}, c^{2}$, and $r$ for 10 replicates for each of the 10 parameter combinations) and in Table 3 (empirical standard deviations as well as the largest and smallest estimates of $h^{2}$ and $r$ for the 10 replicates).

Comparison of the middle three and right three columns of Table 2 confirms the algebra of the simple model used to develop the relationship between the analyses with multiple-trait and repeated-records models. In fact, the first few replicates showed this result. Comparisons for individual replicates agreed well, although with more variation than with the average of 10 replicates. The most noticeable pattern shown in Table 2 is that repeatabilities from the repeatedrecords analyses and phenotypic correlations from the multiple-trait analyses were essentially equal, as might be expected. The average heritability and genetic correlation for the multivariate model underestimated heritability slightly for the repeated-records model for the first eight combinations of underlying parameters but not for the last two, which on the underlying normal scale had 
large genetic correlations with corresponding zero or slightly negative environmental covariances. Consequently, for the first eight combinations the $\mathrm{c}^{2}$ term for repeated records was overestimated from the multivariate model and underestimated for the last two combinations of parameters. These results may be due to environmental covariances in the multivariate analyses being in the genetic component of variance in the repeated-records analysis. Nevertheless, differences between the heritability and $c^{2}$ terms for the repeated-records model and those predicted from the multivariate model are slight for the parameter combinations simulated.

The empirical standard deviations with $9 \mathrm{df}$ shown in Table 3 for heritability estimates are relatively similar for all combinations of parameters. Thus, the pooled standard deviation would be about .020 , which would be an approximate standard error for the heritability estimate of .12 shown in Table 3 of Van Vleck et al. (1981) for the data set for ovulation rate. The standard deviations of repeatability estimates are slightly smaller than for heritability estimates.

\section{Conclusion}

When assumptions for a repeatability model are wrong, then the consequence may be that heritability is underestimated, as found in this study. The assumption violated in this study is the assumption implied in a repeated-records animal model that the genetic correlation between consecutive records is unity. Another assumption of a repeatability model is that the environmental correlations are the same for all pairs of records, but that problem was not addressed. Multivariate covariance estimation from an actual data set yielded average genetic correlations of about .66 . In retrospect, that result suggests that the repeated-records model is incorrect for these data. The intuitive assumption was that the genetic correlation among all pairs of measures was near unity. In fact, the genetic correlation on the normal scale may be near unity because truncation of normal variables with high genetic correlations to binomial variables seems to decrease the apparent genetic correlations to 50 to $60 \%$ of those on the normal scale Van Vleck and Gregory, 1982). That the apparent heritability for a repeated-records model is approximately the product of genetic correlation and heritability from a multitrait analysis was confirmed for combinations of parameters used for simulation. The algebraic explanation is somewhat limited by the simple model used because of the difficulty of doing the algebra with an animal model involving a numerator relationship matrix. Despite that limitation, the algebraic explanation, although an approximation, was effective in all 100 data sets in predicting the variance estimates for a repeatedrecords model.

\section{Implications}

The simulation and the algebraic approximation show that failure of a statistical model to account for covariances among genetic and environmental effects on repeated records can lead to biased estimates of parameters such as heritability that are used in selection programs. To determine whether such biases will result in serious errors in selection will require further analysis.

Table 3. Empirical standard deviations $(S D)$ and maximum and minimum of estimates of heritability and repeatability for a repeated-records model from 10 replications and each of 10 combinations of parameters for an underlying multivariate normal distribution with normal records truncated to binomial records

\begin{tabular}{|c|c|c|c|c|c|c|c|c|}
\hline \multirow{2}{*}{\multicolumn{3}{|c|}{$\begin{array}{c}\text { Underlying multivariate } \\
\text { normal scale }\end{array}$}} & \multicolumn{6}{|c|}{ Estimates from repeated-records animal model } \\
\hline & & & \multicolumn{3}{|c|}{ Heritability } & \multicolumn{3}{|c|}{ Repeatability } \\
\hline$h^{2}$ & $\mathbf{r}_{\mathbf{g}}$ & $\mathbf{r}_{\mathbf{p}}$ & SD & Max & Min & SD & Max & Min \\
\hline .15 & .50 & .20 & .020 & .086 & .007 & .008 & .110 & .083 \\
\hline .15 &.$\theta \bar{\theta}$ & .20 & .022 & .091 & .008 & .013 & .116 & $.07 \theta$ \\
\hline .15 & .90 & .20 & .023 & .081 & .020 & .017 & .123 & .071 \\
\hline .25 & .50 & .20 & .018 & .092 & .042 & .014 & .118 & .077 \\
\hline .25 &.$\theta \bar{\theta}$ & .20 & .026 & .101 & .020 & .013 & .121 & .078 \\
\hline .25 & .80 & .20 & .014 & .098 & .051 & .015 & .114 & .057 \\
\hline .35 & .50 & .25 & .016 & .085 & .051 & .010 & .125 & .082 \\
\hline .35 & $.6 \overline{8}$ & .25 & .018 & .124 & .068 & .018 & .151 & .080 \\
\hline .35 & .90 & .25 & .021 & .137 & .068 & .019 & .138 & .078 \\
\hline .25 & 1.00 & .25 & .022 & .159 & .092 & .018 & .160 & .097 \\
\hline
\end{tabular}




\section{Literature Cited}

Graser, H.-U., S. P. Smith, and B. Tier. 1887. A derivative-free approach for estimating variance components in animal models by restricted maximum likelihood. J. Anim. Sci. 64: 1382 .

Henderson, C. R. 1953. Estimation of variance and covariance components. Biometrics 8:226.

Meyer, K. 1885. Maximum likelihood estimation of variance components for a multivariate mixed model with equal design matrices. Biometrics 41:153.

Meyer, K. 1986. Restricted maximum likelihood to estimate genetic parameters-in practice. Proc. 3rd World Congr. Genet. Appl. Livest. Prod. Lincoln, NE. Vol. XII:454.

Meyer, K. 1988. DFREML, a set of programs to estimate vari- ance components under an individual animal model. J. Dairy Sci. 71(Suppl. 2):33.

Meyer, K. 1989. Restricted maximum likelihood to estimate variance components for animal models with several random effects using a derivative-free algorithm. Genet. Sel. Evol. 21:317.

Smith, S. P., and H.-U. Graser. 1986. Estimating variance components in a class of mixed models by restricted maximum likelihood. J. Dairy Sci. 69:1156.

Van Vleck, L. D., and K. E. Gregory. 1802. Multiple-trait restricted maximum likelihood for simulated measures of ovulation rate with underlying multivariate normal distributions. J. Anim. Sci. 70:57.

Van Vleck, L. D., K. E. Gregory, and S. E. Echternkamp. 1981. Ovulation rate and twinning rate in cattle: Heritabilities and genetic correlation. J. Anim. Sci. 68:3213. 